\title{
PERSPECTIVAS TEÓRICAS SOBRE DESENVOLVIMENTO REGIONAL
}

\author{
Lucas Henrique Campos Vasconcelos ${ }^{1}$ \\ Ideni Terezinha Antonello ${ }^{2}$
}

\section{Resumo}

O debate sobre o desenvolvimento regional desigual se consolidou como um tema de grande importância na literatura que aborda o crescimento e o desenvolvimento econômico. Teorias foram e são formuladas com a finalidade de explicar e corrigir os desequilíbrios regionais, alcançando influência tanto no âmbito do ambiente acadêmico quanto no das políticas públicas. A esse respeito, o objetivo deste artigo é apresentar uma síntese de algumas abordagens teóricas que trabalharam, direta ou indiretamente, com o tema, desde as clássicas até às contemporâneas. Para isso, a produção teórica foi divida em três partes, sendo elas: teorias espaciais ou da localização, teorias clássicas de desenvolvimento regional e abordagens recentes de desenvolvimento regional. Destaca-se que essa divisão foi realizada conforme propõe a maioria dos estudiosos da área, visto que as teorias agrupadas possuem linhas de pensamentos e influências semelhantes, ou seja, não se buscou discorrer as teorias de forma cronológica.

Palavras-chave: Teorias espaciais ou da localização; Teorias clássicas de desenvolvimento regional; Abordagens recentes de desenvolvimento regional.

\section{THEORETICAL PERSPECTIVES ABOUT REGIONAL DEVELOPMENT}

\begin{abstract}
The debate about unequal regional development has consolidated as a very important topic in the literature that addresses growth and economic development. Theories have been and are formulated with the objective of explaining and correcting the regional imbalances, reaching influence both in the scope of the academic environment as in the public policies. In this respect, the purpose of this article is to present a synthesis of some theoretical approaches that have worked, directly or indirectly, with the theme, from the classic to the contemporary. For this, the theoretical production was divided in three parts, being: spatial or localization theories, classic theories of regional development and recent approaches of regional development. It should be noted that this division was carried out as proposed by most scholars in the area, since the grouped theories have lines of thought and similar influences, in other words, this article did not seek to discuss the theories chronologically.
\end{abstract}

1 Mestrando em Geografia pela Universidade Estadual de Londrina (UEL). E-mail: lucasig1000@hotmail.com.

${ }^{2}$ Professora associada do Curso de Graduação e Pós-Graduação em Geografia da Universidade Estadual de Londrina (UEL). E-mail: antonello.uel@gmail.com. 
Keywords: Space or location theories; Classic theories of regional development; Recent regional development approaches.

\section{PERSPECTIVAS TEÓRICAS SOBRE DESARROLLO REGIONAL}

\section{Resumen}

El debate sobre el desarrollo regional se consolidó como un tema de gran importancia en la literatura que aborda el crecimiento y el desarrollo económico. Las teorías fueron desarrolladas con la finalidad de explicar y corregir los desequilibrios regionales, alcanzando influencia tanto en el ámbito académico como así también en los ambientes de las políticas públicas. Este artículo tiene el objetivo de presentar unas síntesis de algunos abordajes teóricos que trabajaran directamente o indirectamente con el tema, desde las clásicas hasta a las contemporáneas. Así que, la producción teórica fue dividida en tres partes: Teorías espaciales o de localización, teorías clásicas de desarrollo regional y abordajes recientes de desarrollo regional. Destáquese que esa división fue realizada conforme propone la mayoría de los investigadores del área, teniendo en cuenta que las teorías agrupadas poseen líneas de pensamientos e influencias semejantes, o sea, no se buscó discurrir las teorías de forma cronológica.

Palabras-Clave: Teorías espaciales o de localización; Teorías clásicas de desarrollo regional; Abordajes recientes de desarrollo regional.

\section{INTRODUÇÃO}

Partindo de diversos questionamentos - o que é desenvolvimento? Como e por que ele ocorre? Como pode ser medido...?, uma vasta literatura acerca do tema foi sendo formulada ao longo do tempo. Incontáveis abordagens e teorias, em muitas ciências Economia, Geografia, História, Sociologia... - e nas diversas escalas territoriais - nacional, regional ou local, foram propostas (BELLINGIERI, 2017).

Contudo, apesar dos avanços com relação à temática, ainda não há um consenso na literatura sobre as causas que fundamentam o desenvolvimento econômico desigual, seja ele no âmbito nacional, regional ou local. De modo geral, é considerado que o desenvolvimento não ocorre homogeneamente no espaço nem linearmente no tempo em razão da própria essência do sistema econômico em vigência, inerentemente desigual.

No que diz respeito à questão regional em particular, algumas perspectivas teóricas trabalharam, direta ou indiretamente, com a presença das desigualdades no desenvolvimento regional, obtendo expressiva aceitação na pauta das discussões econômicas, políticas e 
sociais, tanto no ambiente acadêmico quanto no das políticas públicas. Nesse contexto, o objetivo deste artigo é discutir brevemente algumas dessas abordagens, desde as tradicionais até as mais recentes.

Para isso, buscou-se transitar, de forma interdisciplinar, em várias áreas do conhecimento, pois conforme ressalta Brandão (2010), nenhum campo disciplinar é minimamente capaz de abarcar a expressiva complexidade do assunto. A presente reflexão possui um caráter analítico, pautado no referencial teórico metodológico efetuado por meio de pesquisas bibliográficas em teses, dissertações, revistas científicas eletrônicas e livros, em uma abordagem qualitativa.

Pondera-se que, neste debate teórico, tem-se a compreensão de desenvolvimento regional como um processo ${ }^{3}$ de mudança estrutural, situado histórica e espacialmente, caracterizado pela dinamização socioeconômica e melhoria da qualidade de vida ao conjunto de sua população (DALABRIDA, 2011).

Além desta introdução, o artigo está dividido em três estruturas principais: sendo elas: "Teorias espaciais ou da localização", "Teorias clássicas de desenvolvimento regional" e "Abordagens recentes de desenvolvimento regional". A primeira contextualiza os modelos de Von Thünen, Weber e Christaller, primeiros teóricos a considerar a questão espacial nas análises econômicas. A segunda apresenta as teorias de Perroux, Myrdal e Hirschman, autores de fortes influências marshallianas e keynesianas. A terceira parte destaca as contribuições da Nova Geografia Econômica, o enfoque teórico sobre clusters, arranjos ou sistemas produtivos locais e a teoria do Meio Inovador (Le Milieu Innovateur). Por fim, temse a seção com as considerações finais.

\section{TEORIAS ESPACIAIS OU DA LOCALIZAÇÃO}

Até o início do século XIX, os autores, ao elaborarem teorias acerca do desenvolvimento econômico, pouco se atentavam à questão espacial. Assim, as primeiras manifestações sobre $\mathrm{o}$ assunto ocorreram em torno das diferenças de concentração territorial ou produtiva, que seriam as teorias espaciais ou da localização (BELLINGIERI, 2017). Para Simões (2003), os trabalhos realizados sobre essa temática buscavam estabelecer

\footnotetext{
${ }^{3}$ Assim entendido, como processo, o desenvolvimento não se apresenta como um estágio a ser galgado, um modelo estático a ser seguido (DALLABRIDA, 2011, p. 18).
} 
determinações geográficas ótimas que minimizassem os custos e, em consequência, maximizassem os lucros.

A problemática central para os teóricos das chamadas teorias espaciais ou da localização era construir modelos explicativos, pautados em fórmulas matemáticas, que pudessem indicar as razões das disparidades territoriais ou da concentração das atividades produtivas no interior dos países. Tais teorias buscavam demonstrar os espaços mais propícios para a localização das atividades econômicas, tendo como base os custos de transporte com matéria-prima e também os custos do produto final até o mercado consumidor (DALLABRIDA, 2011). A seguir, serão apresentadas as teorias de Von Thünen, Weber e Christaller, que são considerados os teóricos clássicos das abordagens supracitadas.

\section{Teoria do Estado Isolado de Von Thünen}

Em 1826, o alemão Von Thünen publicou uma obra denominada “O Estado Isolado", que viria, mais tarde, ser considerada pioneira no tratamento formal da questão espacial na economia. Devido a isso, o autor é considerado o fundador da teoria econômica da localização (CAVALCANTE, 2008). Nessa obra, Thünen se preocupa em construir um modelo teórico, baseado em fórmulas matemáticas, que pudesse explicar as diferenças regionais, pautando-se na qualidade e renda da terra e nos custos de transportes dos produtos agrícolas (DALLABRIDA, 2011).

Já Paul Claval (2005) cita que a questão central para Thünen não era explicar a espacialização das atividades econômicas, mas esclarecer o papel da distância e dos custos de transportes sobre os níveis de lucros. Diante disso, Waibel (1948, p. 04) menciona que Thünen defendia que:

\footnotetext{
Assim, com o aumento da distância da cidade, a produção agrícola deve ser a que de acôrdo com seu valor - exige menores tarifas de transporte e, além disso, a que não se deteriora com facilidade e não precisa ser consumida ainda fresca. Como a despesa de transporte dos produtos do campo, até a cidade, é igual para todos os pontos equiidistantes do mercado urbano, os tipos de cultura agrária situar-se-ão em anéis ou faixas concêntricas, em tôrno da cidade, dispondo-se dos de maior intensidade, êstes próximo ao centro, aos de menor, na periferia do Estado.
}

Nota-se, que de acordo com o autor, em todos os produtos é acrescido um valor, em função dos custos de transporte, e isso varia conforme a distância em relação ao centro consumidor (cidade). Desse modo, seria mais racional que, no entorno das cidades, as terras 
fossem destinadas ao plantio de culturas com os maiores custos de transporte. À medida em que houvesse o afastamento das áreas de consumo, a terra seria usada para a plantação de produtos com os menores custos de transporte. Em resumo, Thünen tem como objetivo demonstrar que a renda que se obtém da terra está estreitamente relacionada à distância do mercado, ou seja, as terras mais próximas às cidades (centro consumidor) possuem mais possibilidade de renda em comparação às áreas mais distantes, devido aos custos de transporte.

Nessa concepção, os produtos agrícolas deveriam se distribuir de forma concêntrica no entorno do centro consumidor. Assim sendo, os produtos perecíveis (verduras, frutas, flores e leite) ou de difícil transporte (lenha e materiais para construção) deveriam se localizar próximos às cidades. Nas demais áreas, conforme o distanciamento em relação às áreas de consumo, estariam o cultivo de cereais e a pecuária. Por fim, nas localizações muito distantes, não haveria muitas culturas, pois, os custos de transportes seriam muito elevados (WAIBEL, 1948).

Na mesma linha de raciocínio Fujita, Krugman e Venables (2002) ressaltam que o modelo de Thünen supõe que, em razão dos custos de transporte até a cidade, as taxas de lucros dos fazendeiros, advindas dos produtos agrícolas, seriam mais elevadas nos arredores das cidades e declinaria conforme mais afastado fosse o cultivo.

O modelo proposto por Thünen foi de suma importância para pensar a economia por meio de uma perspectiva espacial, visto que pôde demonstrar a distribuição desigual das atividades agrícolas no território em função dos diferentes custos do transporte, além de dar subsídios para outras teorias espaciais. No entanto, para Cavalcante (2008) trata-se de um modelo estático, que despreza o papel da tecnologia e da capacidade do homem de criar novas possibilidades.

\section{A Teoria da Localização Industrial de Weber}

Em 1909, o alemão Alfred Weber afirma que a localização de uma unidade produtiva (indústria) no espaço geográfico decorre da ponderação de três fatores: custo de transporte, custo de mão de obra e um fator local, resultado das forças internas de aglomeração e desaglomeração (CAVALCANTE, 2008). Em outras palavras, a questão central que Weber propõe discutir com a sua teoria é determinar a melhor localização de uma indústria no território, considerando as condições de produção e distribuição. 
Para fundamentar tal teoria, o autor cria um modelo que parte da premissa que as matérias-primas podem ser classificadas em dois tipos: ubíquas e localizadas. As matériasprimas ubíquas são aquelas disponíveis em diversas partes do espaço e não exercem influências na localização das atividades econômicas; já as localizadas correspondem pelas matérias-primas específicas de uma região e, por isso, podem ter peso determinante na localização das atividades econômicas, à medida que nelas é incorporado algum custo durante o processo de produção ou no produto final (CAVALCANTE, 2008).

Se os custos de transporte com matérias-primas forem superiores aos custos de transporte do produto final, a indústria tenderia a se localizar nas proximidades das matériasprimas; caso contrário, a atividade estaria localizada próxima ao mercado consumidor. Isso significa que o processo de beneficiamento da matéria-prima tem estreita relação com a localização, conforme seu peso no custo final do produto. Nota-se, portanto, como já foi mencionado, que tal teoria se baseia, entre outras coisas, na ponderação entre custo de transporte e produção (SIMÕES, 2003).

A esse respeito, pode-se dizer que os trabalhos de Weber centram seus argumentos no papel que os custos de transporte e produção desempenham na localização das indústrias. Entretanto, conforme ressalta Cavalcante (2008), Weber também reflete sobre outros fatores como aglomeração e desaglomeração, embora não os trate de forma objetiva e aprofundada como as demais variáveis enfocadas pelo autor.

\section{Teoria dos Lugares Centrais de Christaller}

Dando continuidade à produção das teorias da localização, em 1933, Walter Christaller, geógrafo alemão, buscou entender os fenômenos que determinam o número, tamanho e distribuição das cidades, que eram entendidas como "lugares centrais", visto que é a partir delas que ocorre a distribuição de bens e serviços para as áreas ao entorno (CAVALCANTE, 2008).

A Teoria dos Lugares Centrais mostra uma organização espacial da população de acordo com a importância e o dinamismo das atividades econômicas, principalmente o comércio e a indústria. A proximidade de centros industriais e comerciais faz com que a distribuição da população se de em torno desses pólos aglutinadores, ou seja, uma polarização ou redes desses centros urbanos (ALVES, 2011, p. 08). 
Por isso, para fundamentar sua teoria, Chirstaller forja dois conceitos: alcance ou raio de ação de um bem e o limiar mínimo de um bem. Para o autor, o alcance ou raio de ação de um bem ou serviço está relacionado à distância que a população se propõe a percorrer com objetivo de adquirir um bem ou usufruir de um serviço. Já a noção de limiar mínimo de um bem refere-se ao nível mínimo de demanda para assegurar a produção de um determinado bem ou serviço. Assim, os lugares centrais correspondem por aqueles que centralizam tais atributos (BRADFORD; KENT, 1987).

Nota-se que tal teoria parte da hipótese que as cidades possuem uma lógica natural de hierarquização, que tende a formar uma centralização de atividades econômicas em determinados espaços. Nesse sentido, os "lugares centrais" são as cidades, geralmente as de maior porte, responsáveis pelo fornecimento de bens e serviços, tanto para si como para as áreas circunvizinhas de menor centralidade.

Portanto, o modelo posiciona a cidade, sobretudo as de maior dimensão, como local central de onde o poder e as decisões são emanados, com o campo e as pequenas cidades, por sua vez, sendo subordinados às decisões dos centros urbanos dinâmicos. Assim, a relação campo-cidade passa a ter um caráter evidentemente assimétrico, pois as cidades, especialmente as de maior porte, são os lugares de comando e o campo refere-se às áreas que obedecem.

\section{TEORIAS CLÁSSICAS DE DESENVOLVIMENTO REGIONAL}

As teorias clássicas da localização foram de grande relevância para pensar a distribuição espacial da economia. Contudo, Amaral Filho (2001) pondera que essas teorias foram consideradas estáticas e limitadas para compreender o fenômeno dos diferentes estágios de desenvolvimento nas regiões, devido à concentração de suas análises apenas nos custos e nos lucros para a definição da localização ótima de uma firma em uma determinada localidade.

Diante disso, na década de 1950, começaram a surgir uma série de teorias que passaram a dar ênfase a outros fatores, como as externalidades resultantes da aglomeração industrial, os ganhos de escala e a complementariedade entre firmas e setores. Dentre os autores que ocasionaram um relevante avanço nos estudos referentes ao desenvolvimento regional e que terão suas teorias apresentadas a seguir, destacam-se o francês François Perroux, que se notabilizou pela teoria denominada "Polos de Crescimento"; o sueco 
Gunnar Myrdal, que postulou a "Teoria da causalidade cumulativa"; e o alemão Albert Hirschman, que introduziu na literatura econômica o conceito de linkagens - efeitos para trás e para frente.

Tais abordagens têm forte influência marshalliana e, principalmente, dos trabalhos do economista John Maynard Keynes, que defendia a intervenção do Estado na gestão da procura agregada, porque acreditava que somente "a mão invisível do mercado" não conseguia proporcionar equilíbrio ao sistema econômico que, em consequência, ampliava as desigualdades regionais (CAVALCANTE, 2008).

\section{Os polos de crescimento de Perroux}

O conceito polos de crescimento ${ }^{4}$ deu origem a diversas construções teóricas e delas foram extraídas uma série de políticas públicas de desenvolvimento. Presumindo que o crescimento não ocorre uniformemente no espaço nem linearmente no tempo, a teoria tem como foco os processos acumulativos e de localização que podem ser gerados pela interdependência industrial, entorno de uma indústria líder e inovadora (DALLABRIDA, 2011).

Devido ao papel desempenhado pelas inovações na dinâmica capitalista, François Perroux, na década de 1950, propõe-se a compreender o funcionamento interno das aglomerações industriais. Para isso, divide as indústrias em dois tipos: motrizes e movidas. As motrizes normalmente localizam-se no centro do polo de crescimento e têm como característica gerar economias externas e dinamizar a economia; as movidas, por sua vez, situam-se nas áreas periféricas do polo de crescimento e possuem como função fornecer produtos para as indústrias motrizes, à medida que têm suas vendas ampliadas (CAVALCANTE, 2008).

Dessa maneira, o crescimento é geograficamente concentrado e dependente do desempenho das indústrias motrizes de produzir economias de escalas com potencial de gerar grandes efeitos multiplicadores na sua envolvência, como a atração de novos investimentos na forma de indústrias movidas, por exemplo. Logo, as decisões das indústrias

\footnotetext{
${ }^{4}$ Atualmente, polo de crescimento ou polo industrial é uma determinada área no qual concentra uma série de atividades industriais ou empresariais que podem ou não manter relações entre si. No caso particular da teoria de Perroux, as indústrias mantêm uma relação de interdependência.
} 
líderes (indústria motriz) tendem a causar significativos desdobramentos no polo de crescimento.

A longo prazo as aglomerações industriais (polos de crescimento), de dimensões variáveis, geram efeitos polarizadores de diversas vertentes: capital, mão de obra e investimentos públicos, ou seja: drenam e concentram recursos. A partir de um determinado estágio de evolução (a longo prazo) surgirão efeitos de propagação, isto é, difusão de crescimento econômico, mais ou menos de modo concêntrico (VALE, 2010). De forma análoga, Dallabrida (2011) cita que o polo de crescimento pode torna-se um polo de desenvolvimento quando desencadear transformações estruturais e expandir a produção e os empregos para as áreas circunvizinhas.

Após os anos de 1950, aproximadamente 28 países, inclusive o Brasil, chegaram a discutir ou implementar políticas públicas de desenvolvimento regional fundamentadas na teoria dos polos de crescimento. Porém, na década de 1970, sua eficácia começou a ser questionada veementemente. Diversas experiências de desenvolvimento regional fundamentadas nessa concepção haviam em sua maioria falhado, pois as aglomerações indústrias expandiam-se, mas seus efeitos de propagação regional não chegavam a atingir os níveis esperados (ALVES, 2016).

\section{Teoria da causalidade circular cumulativa}

A teoria da causalidade cumulativa tem sua origem na década de 1950 nos pressupostos de Gunnar Myrdal, filiado às correntes keynesianas de crescimento divergente, em oposição aos modelos neoclássicos caracterizados pelo equilíbrio econômico entre as regiões a longo prazo, por via da autorregulação do mercado - "a mão invisível do mercado" (VALE, 2010).

De acordo com essa abordagem, verifica-se movimentos de concentração geográfica das atividades econômicas, resultante de processos de causalidade circular que geram efeitos cumulativos nas regiões, agravando as fraturas territoriais (DALLABRIDA, 2011). Em outras palavras, algumas empresas podem obter benefícios decorrente da aglomeração espacial de um conjunto de atividades que, por sua vez, estimulam a atração de novos investimentos e efeitos de polarização, os quais reforçam os desequilíbrios regionais. 
O [...] poder de atração de um centro econômico se origina principalmente em um fato histórico fortuito, isto é, ter-se iniciado ali com êxito um movimento [...]. Daí por diante, as economias internas e externas sempre crescentes fortificaram e mantiveram seu crescimento contínuo às expensas de outras localidades e regiões, onde, ao contrário, a estagnação ou a regressão relativa se tornou a norma (MYRDAL, 1972, p. 52).

A curto e médio prazo, a concentração de fatores de produção em determinadas regiões gera backwash effects (feitos de bloqueio) em outros espaços, porque os territórios dinâmicos atraem capitais e recursos humanos e, em consequência, bloqueiam o desenvolvimento de outras regiões. Por outro lado, a teoria pressupõe que a longo prazo possam surgir spread effects (efeitos de propagação) da região desenvolvida em direção às áreas desfavorecidas, devido à desconcentração das atividades econômicas. Para a teoria, esse processo pode ser estimulado pelo Estado (ALVES, 2016; VALE, 2010) por meio de investimento em infraestrutura, mão de obra qualificada e subsídios fiscais.

Assim, Cavalcante (2008) lembra que de acordo com Myrdal (1972), o processo de causação circular e cumulativa opera no sentido de ampliar as desigualdades, tanto em nível de Estado-Nação, como também no interior deles, em nível regional por exemplo. Na contramão das teorias neoclássicas, que defendem um processo natural de convergência de renda inter-regional nos países em longo prazo, essa abordagem advoga a necessidade de atuação do Estado na economia para conter as forças do mercado que, de outra forma, geram efeitos perversos sobre a dinâmica socioeconômica.

\section{Os efeitos para frente e para trás de Hirschman}

Adotando a linha de pensamento keynesiana, o alemão Albert Hirschman (1961) cita que os países (ou regiões) "subdesenvolvidos” encontravam-se em tal situação porque se defrontavam com dificuldades para realçar e estabelecer condições necessárias para atrair capital, investimento em infraestrutura e aprimorar a educação técnica e o sistema bancário, que seriam requisitos importantes para "alcançar" o desenvolvimento. Nesse contexto, Hirschman defendia que por meio do Estado, fossem criadas estratégias para alavancar o desenvolvimento.

Em outras palavras, o autor sustentava que o Estado deveria assumir o planejamento e a coordenação do processo de desenvolvimento econômico e regional, porque segundo ele, forças "poderosas" provocam uma concentração espacial do 
crescimento econômico e nesse sentido, o investimento público tem capacidade de orientar e modificar os índices de desenvolvimento de diferentes áreas de um país.

Para defender essa perspectiva, Hirschman (1961) introduz os conceitos de forward linkages (efeitos para a frente) e de backward linkages (efeitos para trás). Os efeitos para frente correspondem pelas externalidades decorrentes da implantação de indústrias que, ao aumentarem a demanda de insumos no setor a montante, viabilizariam suas escalas mínimas de produção na região determinada. Os efeitos para trás resultariam da oferta de insumos, que tornaria viáveis os setores que se posicionassem a jusante (CAVALCANTE, 2008). Assim, para uma região se desenvolver, suas atividades industriais teriam de gerar altos níveis de efeitos de encadeamentos, sobretudo para trás (DALLABRIDA, 2011).

\section{ABORDAGENS RECENTES DE DESENVOLVIMENTO REGIONAL}

Com base nas teorias de Perroux, Myrdal e Hirschman, várias iniciativas foram empreendidas com a finalidade de auxiliar o desenvolvimento das regiões menos prósperas. Porém, no final dos anos de 1970, a crise econômica e a manutenção ou mesmo a divergência regional começaram a colocar esses modelos em xeque.

Concomitantemente a esse cenário, o declínio do sistema keynesiano-fordista, caracterizado pelas economias de escala, e a ascensão do modelo de acumulação flexível, baseado na eletrônica e na informática, culminou na redução das plantas industriais, na terceirização da produção e na formação de redes entre produtores e consumidores.

O modelo keynesiano-fordista pautado nos vultuosos investimentos públicos em grandes empresas industriais localizadas prioritariamente nas grandes metrópoles, tinha como foco o desenvolvimento macroeconômico. Já no modelo de acumulação flexível, as escalas regionais e locais começaram a se tornar prioritárias, conforme os governos centrais transferiam as estratégias de desenvolvimento para as estâncias inferiores (estados e municípios) (BELLINGIERI, 2017).

Por isso Vale (2010) lembra que o desenvolvimento regional pautado na industrialização e no planejamento público começou a ser abandonado, em favor de outras orientações teóricas que privilegiavam novos estudos de mudanças estruturais. Logo, o foco de análise deslocou-se para a investigação das condições sociais, tecnológicas e institucionais que permitiam a alguns espaços manterem elevados níveis de crescimento 
mesmo em períodos de crise, como o caso do Vale do Silício e da Terceira Itália, por exemplo.

Portanto, nesta parte da discussão teórica haverá uma breve revisão das teorias que, após a década de 1980, assumiram o protagonismo nas análises e políticas de desenvolvimento regional. A contribuição da Nova Geografia Econômica (NGE), do enfoque teórico sobre cluster, arranjos ou sistemas produtivos locais e a teoria do Meio Inovador (Le Milieu Innovateur) serão as perspectivas teóricas brevemente expressadas a seguir.

\title{
Nova Geografia Econômica - NGE
}

Nos últimos anos, a Nova Geografia Econômica tem concentrado uma série de estudos da economia regional (COELHO, 2013). Essas análises, em geral, têm como foco explicar, simultaneamente, o porquê das atividades econômicas se concentrarem em certas localidades, em vez de distribuir-se uniformemente pelo território; quais os fatores responsáveis pela aglomeração produtiva; e os motivos que reforçam ou atenuam as disparidades territoriais nas diversas escalas (DALLABRIDA, 2011).

\begin{abstract}
Os conceitos por trás das teorias da NGE são simples e buscam explicar um novo período da história econômica do último quartel do século XX, onde as trocas de produtos manufaturados de uma região pelos produtos manufaturados de outra região se tornaram ainda mais intensas, e também correspondem à imensa maioria das trocas mundiais, tendo estas, logicamente, um aumento tanto em quantum como preço e sendo essas realizadas maioritariamente no comércio internacional entre os países desenvolvidos. Essas trocas são explicadas basicamente pelo padrão de aglomeração (...) e pela necessidade de consumo diversificado dos mercados sofisticados dos países desenvolvidos (COELHO, 2013, p. 68).
\end{abstract}

Assim, recentemente a diversificação do consumo e a queda nos custos de transporte têm acelerado as trocas comerciais e, em consequência, contribuído para a sustentação do crescimento econômico e a integração dos mercados nas diversas escalas. Assim, na prática, a NGE tenta explicar o porquê de uma empresa automobilística japonesa exportar para a Alemanha e, por sua vez, o porquê de uma empresa automobilística alemã exportar para o Japão, assim como os motivos que levaram essas empresas a terem se desenvolvido e se instalado nesses países (COELHO, 2013).

Segundo Vale (2010), a queda nos custos de transporte diminuiu a importância de seus custos e da proximidade às matérias-primas, assim aumentou a importância das 
infraestruturas técnicas e do capital ${ }^{5}$ intangível, como fatores de atração de atividades de maior intensidade e complexidade tecnológica. No plano espacial, esse processo colaborou para a concentração econômica e dos trabalhadores nas regiões mais desenvolvidas e nas cidades de maior porte, propiciando a ampliação das desigualdades regionais.

A teoria defende que os países e regiões mais desenvolvidos tendem a produzir bens com rendimentos crescentes e se beneficiam dos efeitos de mercados. Dessa maneira, é gerado um processo de aglomeração que faz com que as indústrias busquem sua localização nas regiões mais dinâmicas e nas cidades de maior porte, onde os salários são mais elevados e induzem a imigração de mão de obra, contribuindo para o alargamento do mercado. Apenas em um horizonte distante, de acordo com a NGE, poderia ser observado efeitos de espraiamento para as regiões periféricas e cidades de menor dimensão, reduzindo o nível de desigualdade regional.

De forma semelhante Dallabrida (2011), cita que as regiões mais desenvolvidas e as cidades de maior porte possuem atividades produtivas capazes de gerar altos níveis de encadeamentos (linkages) para trás e para frente, que produzem uma dinâmica circular de aglomeração. Contudo, lembra que a imobilidade de recursos, a terra e em alguns casos a força de trabalho, atuam como uma força centrífuga que se opõe a força centrípeta da aglomeração ${ }^{6}$. Assim, a tensão dessas duas forças modela a evolução da estrutura espacial da economia (ALVES, 2016), gerando um nivelamento das disparidades regionais.

Portanto, nota-se que a NGE tem como foco compreender os fatores e as vantagens que concentram as atividades produtivas em determinada localização. Para essa análise, a teoria considera os custos de transporte, a diversificação do consumo e a tensão entre forças que atraem (centrípetas) e repulsam (centrifugas) a atividade econômica.

\footnotetext{
${ }^{5} \mathrm{O}$ capital intangível refere-se a todas as formas de capital imaterial, como capital intelectual, capital humano e capital organizacional, por exemplo. A partir da década de 1970, várias teorias e experiências empíricas ressaltam o papel fundamental da formação de redes de cooperação, da inovação e da tecnologia (capital intangível) no processo de crescimento e desenvolvimento econômico (HERSCOVICI, 2007).

${ }^{6}$ De forma mais abrangente, Alves (2016, p. 64) destaca que "forças centrípetas são todos os elementos que impulsionam a formação de aglomerações e forças centrífugas são as que favorecem a dispersão da atividade económica".
} 


\section{Clusters, arranjos ou sistemas produtivos locais}

A partir do final da década de 1970, a experiência europeia, especialmente do caso bem-sucedido da região conhecida como "Terceira Itália", tornou a discussão sobre clusters, arranjos ou sistemas produtivos locais cada vez mais recorrente no meio acadêmico, incorporando contribuições da economia da inovação, economia industrial e geografia econômica (SCHMITZ; NADVI, 1999).

De modo geral, os clusters ou sistemas produtivos locais, podem ser definidos como novas formas de organização da produção, baseadas na divisão social do trabalho entre as empresas e na criação de um sistema de intercâmbios locais que resultam no aumento da produtividade e no crescimento econômico. Portanto, espera-se que a interação entre empresas propicie desenvolvimento em escala local/regional (KELLER, 2008).

Para Michael Poter (1993), considerado precursor do conceito cluster, a competitividade de um país, de modo geral e simplificado, é reflexo da competividade das aglomerações produtivas (clusters) desse território. Logo, não são os países, mas os clusters que, efetivamente, competem a nível internacional e que determinam o ritmo de desenvolvimento e as vantagens competitivas dos países.

Os clusters, por consistirem em um conjunto de empresas que se comunicam por possuírem características semelhantes e coabitar no mesmo local, possibilitam a colaboração entre empresas, tornando-as mais eficientes, ainda que a proximidade física não implique necessariamente na existência de cooperação entre as empresas. Porém, quando há cooperação, elas têm potencial de incentivar a inovação e estimular o surgimento de novas empresas complementares ao tipo de produção local (DALLABRIDA, 2011).

Por sua vez, Schmitz e Nadvi (1999) enfatiza que a formação de clusters poderia deixar uma região ou cidade vulnerável e dependente de alterações exógenas de consumo e tecnologia, porque considera que uma indústria local mais diversificada é menos frágil a fatores externos. Contudo, essa indústria torna-se menos apta a captar os ganhos de eficiência advindos da concentração geográfica e setorial.

\section{Perspectiva do Meio Inovador (Le Milieu Innovateur)}

O conceito de meio inovador foi difundido pelo Groupe de Recherche Européen pour lês Milieux Innovateurs (GREMI) nos anos de 1980. Nessa abordagem, a inovação não ocorre 
isoladamente a partir das empresas, mas parte do "meio" (território ou região) com capacidade inovativa mediante a formação de redes locais inovadoras (ALVES, 2016). Nesse sentido, o meio assume a função de gerar efeitos dinâmicos e inovadores, em razão da existência de processos de aprendizagem coletivos e redução de incertezas e riscos associados à inovação e aos efeitos de mercado (VALE, 2010).

De modo geral, Cavalcante (2008, p. 25) cita que os autores dessa corrente "[...] preocupam-se com as externalidades de natureza tecnológica que decorreriam dos vínculos de cooperação e interdependência estabelecidos entre as empresas através da formação de redes de inovação". Isto é, a questão central para esta corrente é compreender a influência do meio na geração de processos coletivos de inovação, pois o sucesso ou insucesso regional é orientado pela sua habilidade de gerar inovação.

De acordo com Vale (2010), os meios inovadores articulam-se em torno de três eixos estruturantes da dinâmica territorial: tecno-econômico, organizacional e territorial:

\footnotetext{
- O nível tecnológico tem grande centralidade na teoria dos "meios inovadores", entendendo-se, teoricamente, que as transformações do sistema econômico decorrem da mudança técnica e da inovação;

- Ao nível organizacional, destacam-se os mecanismos que permitem, ou impedem, a coordenação entre os atores do meio, ou seja, as relações entre empresas e instituições é considerada decisiva para a inovação e desenvolvimento territorial. - Por último, com o nível territorial afasta-se a ideia de uma geografia da inovação uniforme; ao contrário, a reflexão teórica aponta para uma capacidade diferenciada dos territórios na organização dos recursos (capital, informação, competências, saber-fazer) e dos atores (empresas, instituições, pessoas inovadoras, etc.) necessários à inovação (VALE, 2010, p. 65-66).
}

Complementando, Méndez (2002, p. 70-71) lembra que a presença de alguns ou todos esses eixos não implica necessariamente que o território avance na direção de um desenvolvimento integrado pois, segundo o autor, a formação de um meio inovador, numa perspectiva geográfica complexa, exige a existência de outros aspectos complementares:

- La creación de un cierto clima social, en donde es perceptible cierta movilización en favor del desarrollo local y una permeabilidad a la incorporación de novedades capaces de romper con inercias heredadas que se constatan hoy como ineficaces o injustas.

- La existencia de redes locales de cooperación, formalizadas o de carácter informal, que hacen posible la realización de proyectos comunes, ya sea con objetivos económicos o de otra índole (cultural, apoyo social, etc.) y que en algunos casos pueden concertarse para impulsar de forma directa diferentes formas de innovación. El concepto de capital sinergético propuesto por Boisier resulta coherente con esta visión.

- La presencia de unas instituciones públicas, locales y regionales, que adoptan una actitud protagonista en el apoyo a la innovación y el desarrollo territorial mediante 
la generación de iniciativas propias, la negociación de acuerdos con otras instancias públicas o privadas, al tiempo que aseguran una suficiente participación de la sociedad civil en los procesos de información y decisión. El concepto de governance, o la idea de construir territorios con proyecto, promovida por la DATAR francesa, se adaptan bien a este planteamiento.

- Un esfuerzo de mejora en la formación de los recursos humanos, que puede incluir desde la enseñanza reglada en sus diversos niveles a la cualificación y reciclaje de empresarios y trabajadores, o una adecuada adaptación de la oferta formativa a las demandas y al saber hacer locales.

Nota-se, portanto, que a formação de um meio inovador exige fatores que vão além de elementos puramente econômicos. Ademais, todas essas formas de inovação (tecnológicas, sociais e institucionais) devem ser refletidas no território, pois como salienta Alves (2016), o desenvolvimento regional e local ocorre pela capacidade do território de gerar processos inovadores, visto que nessa abordagem a concorrência entre as regiões (e seu sucesso) faz-se pela inovação, não pelos custos de produção.

\section{CONSIDERAÇÕES FINAIS}

O presente artigo buscou uma melhor compreensão sobre algumas perspectivas teóricas que trabalharam, direta ou indiretamente, com o tema desenvolvimento regional. Com esse intento, abordou-se as teorias clássicas espaciais ou da localização, passando pelas teorias clássicas de desenvolvimento regional até chegar às abordagens recentes de desenvolvimento regional. Ressalta-se que não se buscou esgotar o assunto, mas sim expor brevemente algumas teorias que, de certa forma, tiveram expressiva aceitação no meio acadêmico e no das políticas públicas.

Como síntese geral, este estudo gerou importantes constatações. O primeiro fato verificado foi que a produção teórica relativa ao desenvolvimento regional foi se tornando cada vez mais complexa à medida que o progresso científico e tecnológico causava mudanças socioeconômicas cada vez mais profundas e estruturais.

As teorias clássicas da localização centravam suas análises basicamente na influência que a distribuição dos recursos naturais e os custos de transporte tinham sobre os níveis de lucro e na localização de uma firma. Essas teorias, entretanto, mostraram-se insuficientemente explicativas para a compreensão da dinâmica espacial da economia.

Posteriormente, foi possível identificar que, após a década de 1950, os estudos referentes ao desenvolvimento regional foram bastante profícuos. As teorias clássicas de François Perroux, Gunnar Myrdal e Albert Hirschman introduziram novos fatores para 
explicar as diferenças regionais, abordando também o papel das externalidades decorrentes das aglomerações produtivas em uma região, associando aos ganhos de escala e à competição imperfeita.

Além disso, foi possível verificar que as novas abordagens buscam tratar do desenvolvimento regional não apenas a partir de elementos puramente mercantis, mas também fatores sociais. Nas décadas recentes, várias contribuições teóricas e estudos empíricos têm demonstrado que a origem do sucesso de diversas regiões do mundo está estreitamente relacionada à sua capacidade de gerar conhecimento e inovação e de criar redes de cooperação entre empresas, por exemplo.

Destaca-se, por fim, que a ideia central deste debate não foi escolher ou definir uma ou outra teoria sendo mais adequada para as análises regionais. Pelo contrário, todas as teorias apresentadas têm seus aspectos positivos, mas não quer dizer que são válidas para todos os estudos, especialmente porque foram elaboradas em tempos históricos específicos e em realidades distintas. Nesse sentido, o presente trabalho deixa a temática à espera de novos tratamentos e considerações, visto que no complexo cenário econômico e social da atualidade, as teorias e abordagens relacionadas à dinâmica econômica das regiões se constituem em um dos maiores desafios das políticas públicas.

\section{REFERÊNCIAS}

ALVES, Lucir Reinaldo. Reestruturação produtiva e desenvolvimento local - o caso do Município de Toledo, Estado do Paraná, Brasil. Tese (doutorado) - Instituto de Geografia e Ordenamento do Território, Universidade de Lisboa, Lisboa, 2016, p. 414.

AMARAL FILHO, Jair. A endogeneização no desenvolvimento econômico regional e local. Planejamento e Políticas Públicas, n. 23, p. 261-286, jun. 2001.

BELLINGIERI, Julio Cesar. Teorias do desenvolvimento regional e local: uma revisão bibliográfica. Revista de Desenvolvimento Econômico - RDE, Salvador, BA, v. 2, n. 37, 2017.

CAVALCANTE, Luiz Ricardo Mattos Teixeira. Produção Teórica em Economia Regional: uma proposta de sistematização. Revista Brasileira de Estudos Regionais e Urbanos, São Paulo, vol. 02, n. 1, p. 09-32, 2008.

CLAVAL, Paul. Geografia econômica e economia. GeoTextos, v. 1, n. 1, p. 01-18 2008. 
COELHO, André Luiz Cardoso. (2013). A “velha” geografia econômica da nova geografia econômica: Lösch frente aos demais antecedentes da modelagem. Revista de

Desenvolvimento Econômico - RDE, Salvador, BA, n. 27, 2013.

DALLABRIDA, Valdir Roque. Desenvolvimento Regional: por que algumas regiões se desenvolvem e outras não? 1. ed. Santa Cruz do Sul, EDUNISC, 2011.

DESLAURIERS, Jean-Pierre; KÉRISIT, Michèle. O delineamento da pesquisa qualitativa. IN: POUPART, Jean. Et al. A pesquisa qualitativa: enfoques epistemológicos e metodológicos. $3^{\text {a }}$. ed. Petrópolis: Vozes, 2012.

FUJITA, Masahisa; KRUGMAN, Paul; VENABLES, Anthony James. Economia espacial. São Paulo: Futura, 2002.

HERSCOVICI, Alain. Capital intangível e direitos de propriedade intelectual: uma análise institucionalista. Revista de Economia Política, vol. 27, nº 3, p. 394-412, 2007.

HIRSCHMAN, Albert O. Estratégia do desenvolvimento econômico. Tradução de Laura Schlaepfer. Rio de Janeiro: Fundo de Cultura, 1961.

KELLER, Paulo Fernandes. Clusters, distritos industriais e cooperação interfirmas: uma revisão da literatura. Revista Economia \& Gestão, v. 8, n. 16, p. 30-47, 2008.

BIADFORD, M. G.; KENT, e W. A. Geografia Humana: teorias e suas aplicações. Departamento de Geografia e Planeamento Regional da Faculdade de Ciências Sociais e Humanas da Universidade Nova de Lisboa, Lisboa, 1987.

MÉNDEZ, Ricardo. Innovación y desarrollo territorial: algunos debates teóricos recientes. Eure (Santiago), v. 28, n. 84, p. 63-83, 2002.

MYRDAL, Gunnar. Teoria econômica e regiões subdesenvolvidas. 3. ed. Rio de Janeiro: Saga, 1972.

PORTER, Michael. E. A vantagem competitiva das nações. Rio de Janeiro: Campus, 1993.

SCHMITZ, Hubert; NADVI, Khalid. Clustering and industrialization: introduction. World Development, Oxford, v. 27, n. 9, p. 1503-1514, 1999.

SIMÕES, Rodrigo Ferreira. Localização industrial e relações intersetoriais: uma análise de fuzzy cluster para Minas Gerais. Tese (doutorado) - Instituto de Economia, Universidade Estadual de Campinas (UNICAMP), Campinas, 2003.

VALE, Mário. Conhecimento, inovação e território. Lisboa: Edições Colibri, 2012. 
WAIBEL, Leo. A teoria de Von Thünen sobre a influência da distância do mercado relativamente à utilização da terra: sua aplicação à Costa Rica. Revista brasileira de geografia, v. 10, p. 2-40, 1948.

Recebido em Julho de 2019

Aprovado em Outubro de 2019

Publicado em Dezembro de 2019 